\title{
SYMPTOMS AND CLINICAL SIGNS ASSOCIATED WITH HOSPITAL ADMISSION AND MORTALITY FOR HEART FAILURE
}

\author{
Dirk Devroey ${ }^{1,2}$, Viviane Van Casteren ${ }^{1}$ \\ ${ }^{1}$ Scientific Institute of Public Health, Unit of Epidemiology, Brussels, Belgium \\ ${ }^{2}$ University of Brussels, Department of General Practice, Brussels, Belgium
}

\begin{abstract}
SUMMARY
Little information is available on the predicting factors for hospitalisation and mortality in heart failure. The aim of this study was to determine the symptoms and clinical signs at the time of the diagnosis of heart failure that predict hospitalisation within the first month after diagnosis and mortality within the first six months after diagnosis. Data were prospectively collected during a two-year period by a nationwide network of sentinel family practices. All adult patients for whom the first time the diagnosis of heart failure was clinically suspected were registered. One, six and twelve months after the initial diagnosis, the family physicians completed a follow-up form with questions about the final diagnosis, evolution and outcome. In total 557 patients with confirmed heart failure were recorded (median age $=78$ years). Hospitalisation within the first month after the diagnosis was best predicted by peripheral oedema ( $p=0.001)$, nocturnal dyspnoea $(p=0.022)$ and pleural effusion $(p=0.032)$ at the time of the diagnosis. Six months after the initial diagnosis the mortality was $19 \%$ and after 12 months it was $26 \%$. Mortality within the first six months after the diagnosis was best predicted by age $(p<0.001)$ and pulmonary rales $(p=0.001)$. Peripheral oedema appeared more among the survivors $(p=0.035)$. Peripheral oedema, nocturnal dyspnoea and pleural effusion are highly associated with hospitalisation within the first month after diagnosis.
\end{abstract}

Key words: heart failure, mortality, hospital admission, primary health care

Address for correspondence: D. Devroey, University of Brussels (VUB), Head of the Department of Family Medicine, Laarbeeklaan 103, B-1090 Brussels, Belgium. E-mail: dirk.devroey@vub.ac.be

\section{INTRODUCTION}

Heart failure is one of the leading causes of hospital admission and mortality in patients over the age of 65 in the western world (1). This high number of patients and hospital admissions generates high economic costs in almost all countries (1).

The prevalence of heart failure in the adult population is between 2 and 3\% and rises spectacularly from the age of 75 years. In the age group between 70 and 79 years the prevalence is estimated 10 to $20 \%$ (2). From the Framingham Heart Study the incidence of heart failure has been estimated $0.2 \%$ (3). The incidence almost doubles every decade making heart failure predominantly a disease of the elderly (3). The risk of death in elderly increases more than threefold with heart failure (4). Five years after the diagnosis of heart failure, only $40 \%$ of patients survive (5).

Heart failure is a disease with many symptoms and clinical signs. The diagnosis is often based on these symptoms and clinical signs and in many cases confirmed by diagnostic procedures which try to evaluate the ventricular function.

Thereupon, the new-onset of heart failure is often acute, with symptoms and clinical signs related to fluid retention. The term "acute" is in this context an indicator of time rather than severity. However, new-onset heart failure may also start after myocardial infarction, and in that case acute may be an indicator of severity.
Only little reliable data from primary health care about the symptoms and clinical signs associated with hospital admission and mortality are available for heart failure. These data from primary health care are probably different from those of the patients with heart failure who present in the hospital emergency department because only the worst cases are are seen in the hospitals and patients dying at their residence are not included in hospital figures.

The aim of this study is to determine from a registration in primary health care the symptoms and clinical signs at the time of the diagnosis of heart failure that predict hospital admission within the first month after diagnosis and mortality within the first six months after diagnosis.

\section{MATERIALS AND METHODS}

\section{Sentinel Network}

The data for this study were collected by the Belgian network of sentinel practices. This network has been functioning since 1979 and serves as a reliable source on the surveillance of morbidity in Belgium (6-9). Such a surveillance system has already been tested and proved effective (8-11) and is currently applied in a number of countries (12). It has been adequately proven that the Belgian sentinel practices form an important source of data over a wide range of diseases. 
The network of sentinel practices consists of family physicians who, with respect to age and gender, are representative of family physicians in Belgium. The sentinel practices are distributed evenly over the territory (13).

\section{Case Ascertainment}

The recordings for this study were made by the 178 sentinel practices who regularly participated in the registrations during the period 2005-06. All adult patients for whom for the first time the clinical diagnosis of heart failure was suspected were recorded on the weekly registration form. An additional in-depth questionnaire was sent one month after the initial recording to the physician. The physician was asked to confirm or deny the initial clinical diagnosis of heart failure and to provide more detailed information on diagnostic criteria and complementary examinations. Patients with other causes than heart failure for the non-specific clinical symptoms were dropped out of the study. Six and twelve months after the initial diagnosis, the family physicians personally completed a follow-up form with questions about evolution and outcome. For the present study, hospital admission was evaluated after one month and mortality six months after the initial diagnosis of heart failure. Only hospital admission for heart failure was taken into account. All cases of mortality were taken into account, those related to heart failure as well as those not related to heart failure.

\section{Data Management and Statistical Analysis}

The data of the sentinel practices are entered weekly using a dbase-based software. Databases were stored with a central data manager at the Scientific Institute of Public Health. Several control measures ensured data quality and limited missing data. Data cleaning and data analyses for this study were performed using SPSS17.0 (SPPS Inc). Univariate association between hospitalisation and symptoms/clinical signs was tested by means of $\chi^{2}$ tests. The Fisher exact test was used when less then 10 observations were concerned. Multivariate analyses were performed with backward stepwise logistic regression to look at the association between the symptoms and clinical signs with hospital admission and mortality.

\section{RESULTS}

\section{Registrations and Age}

In total 557 patients with confirmed heart failure were recorded. In total $56 \%$ of the patients with heart failure were women. The median age of the patients with heart failure was 77.7 years $(\mathrm{SD}=10.3$; range 26-101)). Hospital admission within the first month after diagnosis was necessary for $51 \%$ of these patients. The median age of the patients with hospital admission was 77.6 years $(\mathrm{SD}=10.2$; range 26-94)) and for those without hospital admission 77.9 years $(S D=10.4$; range $27-101)(p=0.762)$.

After six months, $19 \%$ of the patients with heart failure died. The median age of the patients not surviving heart failure was 82.7 years $(\mathrm{SD}=9.0$; range $43-101))$ and of the survivors 76.5 years $(\mathrm{SD}=10.2$; range $26-99)(\mathrm{p}<0.001)$.

\section{Symptoms and Clinical Examination}

At the time of the diagnosis, patients complained of breathlessness on exercise in $67 \%$ of cases, limitations of physical activity in $60 \%$, orthopnoea in $46 \%$, tiredness on exercise also in $46 \%$ and nocturnal dyspnoea in $26 \%$. Other complaints such as night cough, oedema and sweating were observed in $12 \%$.

During the physical examination, peripheral oedema was observed in $68 \%$ of the cases, pulmonary rales in $62 \%$, raised jugular venous pressure in $26 \%$, pleural effusion in $23 \%$, cardiac murmurs in $22 \%$, hepatomegaly in $16 \%$ and a third heart sound in $10 \%$. Other clinical signs such as gain of weight, tachycardia and atrial fibrillation were observed in $16 \%$.

At the time of the diagnosis, only few patients were classified as NYHA I (3\%). Most of the patients were classified as NYHA III ( $49 \%), 26 \%$ as NYHA IV and $20 \%$ as NYHA II.

\section{Hospital Admission}

A hospital admission was necessary for $51 \%$ of the patients with newly diagnosed heart failure $(54 \%$ of men and $48 \%$ of women). The patients needing hospital admission within the first month after the diagnosis of heart failure complained significantly more of nocturnal dyspnoea $(\mathrm{p}<0.001)$, orthopnoea $(\mathrm{p}<0.001)$ and breathlessness on exercise $(p<0.048)$ than those not needing hospital admission.

Patients needing hospital admission within the first month after diagnosis presented significantly more with pleural effusion ( $p<0.001)$, pulmonary rales $(p<0.001)$, hepatomegaly $(p=0.004)$, raised jugular venous pressure $(\mathrm{p}=0.014)$ and a third heart sound $(p=0.019)$ than those not needing hospital admission.

To determine the symptoms and clinical signs with the highest association with hospital admission, we built a model on the

Table 1. Symptoms and clinical signs for patients with and without hospital admission within first six months after the diagnosis of heart failure

\begin{tabular}{|l|c|c|c|}
\hline & $\begin{array}{c}\text { Hospital } \\
\text { admission } \\
(\mathrm{n}=274) \\
\mathrm{n}(\%)\end{array}$ & $\begin{array}{c}\text { No hospital } \\
\text { admission } \\
(\mathrm{n}=283) \\
\mathrm{n}(\%)\end{array}$ & p-value \\
\hline Nocturnal dyspnoea & $92(34)$ & $51(18)$ & $<0.001$ \\
\hline Orthopnoea & $154(56)$ & $104(37)$ & $<0.001$ \\
\hline Limitations of physical activity & $171(62)$ & $163(58)$ & 0.25 \\
\hline Breathlessness on exercise & $194(71)$ & $178(63)$ & 0.048 \\
\hline Tiredness on exercise & $134(49)$ & $124(44)$ & 0.23 \\
\hline Other symptoms & $39(14)$ & $26(9)$ & 0.064 \\
\hline Third heart sound & $37(14)$ & $21(7)$ & 0.019 \\
\hline Cardiac murmurs & $59(22)$ & $64(23)$ & 0.76 \\
\hline Pleural effusion & $84(31)$ & $44(16)$ & $<0.001$ \\
\hline Pulmonary rales & $195(71)$ & $149(53)$ & $<0.001$ \\
\hline $\begin{array}{l}\text { Raised jugular venous } \\
\text { pressure }\end{array}$ & $84(31)$ & $61(22)$ & 0.014 \\
\hline Hepatomegaly & $55(20)$ & $32(11)$ & 0.004 \\
\hline Peripheral oedema & $184(67)$ & $197(70)$ & 0.53 \\
\hline Other clinical signs & $48(18)$ & $41(15)$ & 0.33 \\
\hline
\end{tabular}


basis of patient characteristics using backward stepwise logistic regression, with hospital admission for heart failure as the dependent variable. Peripheral oedema, nocturnal dyspnoea and pleural effusion had the best association with hospital admission within the first month after diagnosis.

Patients needing hospital admission within the first month after diagnosis had a higher NYHA classification at the time of the diagnosis than those not needing hospital admission. NYHA IV was found in $39 \%$ of the hospitalized patients compared to $14 \%$ in those not hospitalized $(\mathrm{p}<0.001)$. The patients with NYHA IV were hospitalised in $73 \%$, those with NYHA III in 50\%, those with NYHA II in $25 \%$ and patients with NYHA I in $39 \%$.

\section{Mortality}

Six months after the initial diagnosis of heart failure the mortality was $19 \%$ with no differences between men and women. After 12 months the mortality was $26 \%$ and not significantly higher among women (28\%) than among men (23\%).

The patients dying within six months after the initial diagnosis of heart failure didn't complain significantly more of any symptom

Table 2. Logistic regression stepwise backwards last step for hospital admission

\begin{tabular}{|l|c|c|c|c|c|c|}
\hline \multicolumn{4}{|c|}{} & \multicolumn{2}{|c|}{$\begin{array}{c}\text { 95\% Confidence } \\
\text { Interval for O.R. }\end{array}$} \\
\hline & B & $\begin{array}{c}\text { Std. } \\
\text { Error }\end{array}$ & $\begin{array}{c}\text { p- } \\
\text { value }\end{array}$ & O.R. & $\begin{array}{c}\text { Lower } \\
\text { Bound }\end{array}$ & $\begin{array}{c}\text { Upper } \\
\text { Bound }\end{array}$ \\
\hline $\begin{array}{l}\text { Nocturnal } \\
\text { dyspnoea }\end{array}$ & 0.45 & 0.20 & 0.022 & 1.57 & 1.07 & 2.32 \\
\hline Orthopnoe & 0.30 & 0.17 & 0.084 & 1.35 & 0.96 & 1.89 \\
\hline $\begin{array}{l}\text { Pleural } \\
\text { effusion }\end{array}$ & 0.43 & 0.20 & 0.032 & 1.53 & 1.04 & 2.26 \\
\hline $\begin{array}{l}\text { Pulmonary } \\
\text { rales }\end{array}$ & 0.28 & 0.16 & 0.087 & 1.32 & 0.96 & 1.83 \\
\hline $\begin{array}{l}\text { Peripheral } \\
\text { oedema }\end{array}$ & -0.54 & 0.16 & 0.001 & 0.58 & 0.43 & 0.79 \\
\hline
\end{tabular}

Logistic regression with in the first step gender, age, nocturnal dyspnoea, orthopnoea, limitations of physical activity, breathlessness on exercise, tiredness on exercise, others symptoms, third heart sound, cardiac murmurs, pleural effusion, pulmonary rales, raised jugular venous pressure, hepatomegaly, peripheral oedema and others clinical signs.

Table 3. NYHA classification for patients with and without hospital admission within first six months after the diagnosis of heart failure

\begin{tabular}{|l|c|c|c|}
\hline & $\begin{array}{c}\text { Hospital } \\
\text { admission } \\
(n=274) \\
n(\%)\end{array}$ & $\begin{array}{c}\text { No hospital } \\
\text { admission } \\
(n=283) \\
n(\%)\end{array}$ & p-value \\
\hline NYHAI & $7(2.6)$ & $11(3.9)$ & 0.37 \\
\hline NYHA II & $28(10)$ & $82(29)$ & $<0.001$ \\
\hline NYHA III & $135(49)$ & $137(48)$ & 0.84 \\
\hline NYHA IV & $106(39)$ & $40(14)$ & $<0.001$ \\
\hline
\end{tabular}

at the time of the diagnosis. The physical examination of these patients revealed significantly more pulmonary rales $(\mathrm{p}<0.001)$ and significantly less peripheral oedema $(\mathrm{p}<0.006)$.

To determine the symptoms and clinical signs with the highest association with mortality, we built a model on the basis of patient characteristics using backward stepwise logistic regression, with heart failure mortality within six months as the dependent variable. Age and pulmonary rales had the best association with mortality and peripheral oedema had an inverse association with mortality.

Patients dying from heart failure within six months after the diagnosis had a higher NYHA classification at the time of the

Table 4. Symptoms and clinical signs for patients with and without mortality within first six months after the diagnosis of heart failure

\begin{tabular}{|l|c|c|c|}
\hline & $\begin{array}{c}\text { Death } \\
(\mathrm{n}=108) \\
\mathrm{n}(\%)\end{array}$ & $\begin{array}{c}\text { Survivors } \\
(\mathrm{n}=449) \\
\mathrm{n}(\%)\end{array}$ & $\mathrm{p}$-value \\
\hline Nocturnal dyspnoea & $29(27)$ & $114(25)$ & 0.75 \\
\hline Orthopnoea & $57(53)$ & $201(45)$ & 0.13 \\
\hline $\begin{array}{l}\text { Limitations of physical } \\
\text { activity }\end{array}$ & $60(56)$ & $274(61)$ & 0.30 \\
\hline $\begin{array}{l}\text { Breathlessness on } \\
\text { exercise }\end{array}$ & $69(64)$ & $303(68)$ & 0.48 \\
\hline Tiredness on exercise & $47(44)$ & $211(47)$ & 0.52 \\
\hline Other symptoms & $14(13)$ & $51(11)$ & 0.64 \\
\hline Third heart sound & $14(13)$ & $44(10)$ & 0.33 \\
\hline Cardiac murmurs & $28(26)$ & $95(21)$ & 0.28 \\
\hline Pleural effusion & $28(26)$ & $100(22)$ & 0.42 \\
\hline Pulmonary rales & $82(76)$ & $262(58)$ & $<0.001$ \\
\hline $\begin{array}{l}\text { Raised jugular venous } \\
\text { pressure }\end{array}$ & $31(29)$ & $114(25)$ & 0.48 \\
\hline Hepatomegaly & $19(18)$ & $68(15)$ & 0.53 \\
\hline Peripheral oedema & $62(57)$ & $319(71)$ & 0.006 \\
\hline Other clinical signs & $14(13)$ & $75(16)$ & 0.34 \\
\hline
\end{tabular}

Table 5. Logistic regression stepwise backwards last step for mortality

\begin{tabular}{|l|c|c|c|c|c|c|}
\hline \multicolumn{4}{|c|}{} & \multicolumn{2}{c|}{$\begin{array}{c}9 \% \\
\text { Interval for O.R. }\end{array}$} \\
\hline & B & $\begin{array}{c}\text { Std. } \\
\text { Error }\end{array}$ & p-value & O.R. & $\begin{array}{c}\text { Lower } \\
\text { Bound }\end{array}$ & $\begin{array}{c}\text { Upper } \\
\text { Bound }\end{array}$ \\
\hline Age & 0.06 & 0.01 & $<0.001$ & 1.07 & 1.04 & 1.10 \\
\hline $\begin{array}{l}\text { Pulmonary } \\
\text { rales }\end{array}$ & 0.72 & 0.22 & 0.001 & 2.06 & 1.33 & 3.18 \\
\hline $\begin{array}{l}\text { Peripheral } \\
\text { oedema }\end{array}$ & -0.44 & 0.21 & 0.035 & 0.64 & 0.43 & 0.97 \\
\hline
\end{tabular}

Logistic regression with in the first step gender, age, nocturnal dyspnoea, orthopnoea, limitations of physical activity, breathlessness on exercise, tiredness on exercise, others symptoms, third heart sound, cardiac murmurs, pleural effusion, pulmonary rales, raised jugular venous pressure, hepatomegaly, peripheral oedema and others clinical signs. 
Table 6. NYHA classification for patients with and without mortality within first six months after the diagnosis of heart failure

\begin{tabular}{|l|c|c|c|}
\hline & $\begin{array}{c}\text { Death } \\
(\mathrm{n}=108) \\
\mathrm{n}(\%)\end{array}$ & $\begin{array}{c}\text { Survivors } \\
(\mathrm{n}=449) \\
\mathrm{n}(\%)\end{array}$ & $\mathrm{p}$-value \\
\hline NYHAI & $3(2.8)$ & $15(3.3)$ & 0.77 \\
\hline NYHA II & $8(7.4)$ & $102(23)$ & $<0.001$ \\
\hline NYHA III & $41(38)$ & $231(51)$ & 0.012 \\
\hline NYHA IV & $52(48)$ & $94(21)$ & $<0.001$ \\
\hline
\end{tabular}

diagnosis than those not dying from heart failure. NYHA IV was found in $48 \%$ of the dying compared to $21 \%$ among the the survivors $(\mathrm{p}<0.001)$. The mortality within the first six months among patients with NYHA IV was $36 \%$, for those with NYHA III it was $15 \%$, those with NYHA II in $7 \%$ and patients with NYHA I in $17 \%$.

\section{DISCUSSION}

Half of the patients with newly diagnosed heart failure are hospitalized within the first months after the diagnosis. Six months after the initial diagnosis of heart failure the mortality was $19 \%$. Many symptoms and clinical signs may appear among patients with newly diagnosed heart failure. However, peripheral oedema, nocturnal dyspnoea and pleural effusion are highly associated with hospital admission. But, none of the symptoms or clinical signs are associated with mortality.

\section{Sentinel Network}

Medical records do not always provide detailed information concerning the care provided. Therefore, a registration with predefined questions directly with GP's has an important surplus value. Since primary health care is highly accessible in Belgium, a representative sample of the entire population can be monitored. The Belgian sentinel network of general practices is since many years very stable in terms of participating GP's. The sentinel network is highly performant to monitor health-related problems over long and repeated periods. The participating GP's have not been selected on the basis of a specific interest in heart failure research.

Comparisons between the incidence of stroke mortality and suicide registered with the Belgian Sentinel Network and the figures from the National Institute for Statistics on the one hand, and between the cancer incidence registered via the Belgian Sentinel Network and several national and international cancer registries on the other hand, have shown that the Sentinel Network can provide information representative for the entire Belgian population $(8,14)$.

Because of the weekly registrations, which are leaving little time between the onset of heart failure and the registration, retrospective recall bias found in other retrospective research designs, will be limited $(15,16)$.

Besides the many strengths of the Belgian sentinel network, the system also has some weaknesses. The registration and follow-up forms are to be kept simple, and time-consuming questions should be avoided. Consequently, the in-depth study of some specific aspects of heart failure is not feasible (17). However, for the present registration of heart failure, the participating GP's completed two in-depth follow-up questionnaires after 6 and 12 months.

\section{Prospective Registration}

In many studies, such as the Framingham Heart Study, heart failure was identified by examining at certain intervals individuals within a cohort (3). This implicates a retrospective registration of cases. In more recent registrations data were accessed by population-based surveillance systems in which individuals developing heart failure were prospectively included (18-20). The present registration by the Belgian sentinel network also uses a prospective registration of heart failure which has the advantage that incident cases may be fully characterized at the time of the diagnosis.

\section{Clinical Diagnosis}

The diagnosis of heart failure was strictly clinical in this study. The diagnosis is very difficult in primary health care and many definitions of heart failure have been used over the last 50 years (21). Most of the definitions emphasized the combination of symptoms of heart failure and clinical signs of fluid retention (22). According to the guidelines of the European Society of Cardiology (ESC) heart failure is defined as a clinical syndrome in which patients have symptoms as well as clinical signs typical for heart failure and objective evidence of a structural or functional abnormality of the heart at rest (2). According to the ESC the symptoms typical of heart failure include breathlessness at rest or on exercise, fatigue, tiredness and ankle swelling. The clinical signs typical of heart failure are defined by the ESC as tachycardia, tachypnoea, pulmonary rales, pleural effusion, raised jugular venous pressure, peripheral oedema and hepatomegaly. Objective evidence of a structural or functional abnormality of the heart at rest can be found in cardiomegaly, third heart sound, cardiac murmurs, abnormality on the echocardiogram and raised natriuretic peptide concentration. These diagnostic procedures were not always performed in our study. The participating family physicians were free to perform these procedures, if they though they might be contributive to the diagnosis. However, it is well known that some clinical examinations with a good specificity and sensitivity are underused in family practice (23).

The strength of our study is that the diagnosis of heart failure was confirmed after one month, giving the family physicians the opportunity for further investigations and excluding most of the inaccurate diagnoses. But, most of the diagnostic procedures are not very specific for heart failure. An abnormal electrocardiography has little predictive value for the diagnosis of heart failure. Chest X-ray permits the differential diagnosis with other causes of dyspnoea but has only little power to exclude heart failure. Echocardiography provides insight into the function of the several parts of the heart but can not always confirm or exclude heart failure (24). A normal concentration of natriuretic peptides makes the diagnosis of heart failure unlikely but increased levels have only little predictive value for heart failure. Baseline serum copper is significantly higher in patients with chronic heart failure but the value of copper concentrations in the diagnosis of heart failure is poor (25). 


\section{Hospital Admission and Mortality}

It can be assumed that all hospital admission were related to heart failure because only the hospital admission for heart failure were recorded. But for mortality all cases were taken into account, those related to heart failure as well as those not related to heart failure. Therefore, the present mortality figures need to be interpreted as a total mortality and not only as a heart failure-related mortality.

The participating physicians were asked to provide optimal treatment to their patients. We can assume that the hospitalisation figures and mortality rates are not confound by insufficient treatment of heart failure.

It is generally accepted that more than $50 \%$ of patients diagnosed with heart failure will die within five years of diagnosis (1). This mortality rate is comparable with those for the worst types of cancers (26). Patients requiring hospital admission for heart failure have the worst prognosis. Mortality rates are $10-20 \%$ in the first month after hospital admission and 30-45\% after one year (27-29). These figures are in line with the results of our study where half of the patients are hospitalised within the first month after diagnosis and where $19 \%$ died within the first six months. After 12 months the mortality was $26 \%$ in our study.

Hospital admission was evaluated after one month and mortality after six months. From the registration it was possible to evaluate hospital admission and mortality after 12 months.

Hospital admission within the first month after diagnosis was best predicted by the NYHA classification. NYHA IV was found in $39 \%$ of the hospitalized patients compared to $14 \%$ in those not hospitalized. The patients with NYHA IV were hospitalised in $73 \%$ of the cases.

Patients dying from heart failure within six months after the diagnosis had a higher NYHA classification at the time of the diagnosis than those not dying from heart failure. NYHA IV was found in $48 \%$ of the dying compared to $21 \%$ among the the survivors. The mortality within the first six months among patients with NYHA IV was $36 \%$.

Surprisingly, hospital admission rates and mortality rates were higher among patients with NYHA IV compared to those with NYHA III. However, these figures are probably biased by the low number of patients with NYHA IV.

In our study heart failure was classified according to the NYHA classification. This is a functional classification based on the symptoms of the patients. Other classifications such as the ACC/AHA (30), Forrester (31) and Killip (32) classification exist. They are based on the symptoms and the structure of the heart. Because the functional status of the heart was not investigated for all patients, it was not appropriate to use another classification.

In our study there is no obvious relationship between the occurrence of symptoms and clinical signs at the time of the diagnosis and the risk for hospital admission or mortality. Therefore symptoms and the clinical examination alone should not influence the optimal titration of the treatment. Even for patients with few or mild symptoms the optimal treatment should be initiated from the moment of the diagnosis.

\section{CONCLUSIONS}

Many symptoms and clinical signs may appear among patients with newly diagnosed heart failure. However, peripheral oedema, nocturnal dyspnoea and pleural effusion are highly associated with hospital admission within the first month after diagnosis. But, none of the symptoms or clinical signs are associated with mortality within the first six month after diagnosis. All patients with heart failure should benefit from the most optimal treatment from the moment of the diagnosis.

\section{Acknowledgements}

The authors thank all participating family physicians for the registration of patients and Karolien Vantomme for the comments on the manuscript. The Flemish and French speaking Community fund the Belgian sentinel stations network.

\section{REFERENCES}

1. Stewart S, MacIntyre K, Capewell S, McMurray JJ. Heart failure and the aging population: an increasing burden in the 21st century? Heart. 2003 Jan;89(1):49-53.

2. Task Force for Diagnosis and Treatment of Acute and Chronic Heart Failure 2008 of European Society of Cardiology; Dickstein K, CohenSolal A, Filippatos G, McMurray JJ, Ponikowski P, Poole-Wilson PA, et al. ESC Guidelines for the diagnosis and treatment of acute and chronic heart failure 2008: the Task Force for the Diagnosis and Treatment of Acute and Chronic Heart Failure 2008 of the European Society of Cardiology. Developed in collaboration with the Heart Failure Association of the ESC (HFA) and endorsed by the European Society of Intensive Care Medicine (ESICM). Eur Heart J. 2008 Oct;29(19):2388-442. Erratum in: Eur Heart J. 2010 Apr;12(4):416.

3. Ho KK, Pinsky JL, Kannel WB, Levy D. The epidemiology of heart failure: the Framingham Study. J Am Coll Cardiol. 1993 Oct;22(4 Suppl A):6A-13A.

4. Bonneux L, Barendregt JJ, Meeter K, Bonsel GJ, van der Maas PJ. Estimating clinical morbidity due to ischemic heart disease and congestive heart failure: the future rise of heart failure. Am J Public Health. 1994 Jan;84(1):20-8.

5. McMurray JJ, Stewart S. Epidemiology, aetiology, and prognosis of heart failure. Heart. 2000 May;83(5):596-602.

6. Stroobant A, van Casteren V, Thiers G. Surveillance systems from primary-care data: surveillance through a network of sentinel general practitioners. In: Eylenbosch WJ, Noah D, editors. Surveillance in health and disease. Oxford: Oxford University Press; 1988. p. 62-74.

7. Lobet MP, Stroobant A, Mertens R, Van Casteren V, Walckiers D, MasuyStroobant $\mathrm{G}$, et al. Tool of validation of the network of sentinel general practitioners in the Belgian health care system. Int J Epidemiol. 1987 Dec;16(4):612-8.

8. Devroey D, Van Casteren V, Buntinx F. Registration of stroke through the Belgian sentinel network and factors influencing stroke mortality. Cerebrovasc Dis. 2003;16(3):272-9.

9. Van den Block L, Deschepper R, Bilsen J, Van Casteren V, Deliens L. Transitions between care settings at the end of life in belgium. JAMA. 2007 Oct 10;298(14):1638-9.

10. Grob PR. A morbidity recording system for primary health care. In: Leaverton PE, editor. Environmental epidemiology. New York: Praeger Publishers; 1982. p. 131-9.

11. Collete BJA. The sentinel practices system in the Netherlands. In: Leaverton PE. editor. Environmental epidemiology. New York: Praeger Publishers; 1982. p. 149-55.

12. Deckers JG, Paget WJ, Schellevis FG, Fleming DM. European primary care surveillance networks: their structure and operation. Fam Pract. 2006 Apr;23(2):151-8.

13. Characteristics of sentinel practices: situation in 2007 and comparison with the previous years [Internet]. Brussels: Scientific Institute of Public Health [cited 2009 Nov 15]. Available from: http://www.iph.fgov.be/ epidemio/epinl/medvnl/profil_07.pdf.

14. Van Casteren V, Van der Veken J, Tafforeau J, Van Oyen H. Suicide and attempted suicide reported by general practitioners in Belgium, 19901991. Acta Psychiatr Scand. 1993 Jun;87(6):451-5.

15. Van der Heide A, Deliens L, Faisst K, Nilstun T, Norup M, Paci E, et al; EURELD consortium. End-of-life decision making in six European countries: descriptive study. Lancet. 2003 Aug 2;362(9381):345-50 
16. Teno JM. Measuring end-of-life care outcomes retrospectively. J Palliat Med. 2005;8 Suppl 1:S42-9.

17. Fleming DM, Schellevis FG, Paget WJ. Health monitoring in sentinel practice networks: the contribution of primary care. Eur J Public Health. 2003 Sep;13(3 Suppl):80-4.

18. Hedberg P, Lönnberg I, Jonason T, Nilsson G, Pehrsson K, Ringqvist I. Left ventricular systolic dysfunction in 75-year-old men and women; a population-based study. Eur Heart J. 2001 Apr;22(8):676-83.

19. Kupari M, Lindroos M, Iivanainen AM, Heikkilä J, Tilvis R. Congestive heart failure in old age: prevalence, mechanisms and 4-year prognosis in the Helsinki Ageing Study. J Intern Med. 1997 May;241(5):387-94.

20. Mosterd A, Hoes AW, de Bruyne MC, Deckers JW, Linker DT, Hofman A, et al. Prevalence of heart failure and left ventricular dysfunction in the general population; The Rotterdam Study. Eur Heart J. 1999 Mar;20(6):447-55.

21. PooleWilson PA. History, definition and classification of heart failure. In: PooleWilson PA, Colucci WS, Massie BM, Chatterjee K, Coates ALS, editors. Heart failure: scientific principles and clinical practice. London: Churchill Livingstone; 1997. p. 26977.

22. National Collaborating Centre for Chronic Conditions. Chronic heart failure: national clinical guideline for diagnosis and management in primary and scondary care. London: Royal College of Physicians of London; 2003.

23. Laukkanen A, Ikäheimo M, Luukinen H. Practices of clinical examination of heart failure patients in primary health care. Cent Eur J Public Health. 2006 Jun;14(2):86-9.

24. McCall D. Recognition and management of asymptomatic patients with left ventricular dysfunction. Am J Cardiol. 1992 Jun 4;69(18):130G-139G.

25. Málek F, Dvořák J, Jirešová E, Špaček R. Difference of baseline serum copper levels between groups of patients with different one year mortality and morbidity and chronic heart failure. Cent Eur J Public Health. 2003 Dec;11(4):198-201.

26. Stewart S, MacIntyre K, Hole DJ, Capewell S, McMurray JJ. More 'malignant' than cancer? Five-year survival following a first admission for heart failure. Eur J Heart Fail. 2001 Jun;3(3):315-22.

27. Merlo J, Ostergren PO, Broms K, Bjorck-Linné A, Liedholm H. Survival after initial hospitalisation for heart failure: a multilevel analysis of patients in Swedish acute care hospitals. J Epidemiol Community Health. 2001 May;55(5):323-9.

28. Jong P, Vowinckel E, Liu PP, Gong Y, Tu JV. Prognosis and determinants of survival in patients newly hospitalized for heart failure: a populationbased study. Arch Intern Med. 2002 Aug 12-26;162(15):1689-94.

29. Croft JB, Giles WH, Pollard RA, Keenan NL, Casper ML, Anda RF. Heart failure survival among older adults in the United States: a poor prognosis for an emerging epidemic in the Medicare population. Arch Intern Med. 1999 Mar 8;159(5):505-10.

30. Hunt SA, Abraham WT, Chin MH, Feldman AM, Francis GS, Ganiats TG, et al; American College of Cardiology; American Heart Association Task Force on Practice Guidelines; American College of Chest Physicians; International Society for Heart and Lung Transplantation; Heart Rhythm Society. ACC/AHA 2005 Guideline Update for the Diagnosis and Management of Chronic Heart Failure in the Adult: a report of the American College of Cardiology/American Heart Association Task Force on Practice Guidelines (Writing Committee to Update the 2001 Guidelines for the Evaluation and Management of Heart Failure): developed in collaboration with the American College of Chest Physicians and the International Society for Heart and Lung Transplantation: endorsed by the Heart Rhythm Society. Circulation. 2005 Sep 20;112(12):e154-235.

31. Forrester JS, Diamond GA, Swan HJ. Correlative classification of clinical and hemodynamic function after acute myocardial infarction. Am J Cardiol. 1977 Feb;39(2):137-45.

32. Killip T 3rd, Kimball JT. Treatment of myocardial infarction in a coronary care unit. A two year experience with 250 patients. Am J Cardiol. 1967Oct;20(4):457-64.

Received January14, 2010

Accepted in revised form August 23, 2010 